Article

\title{
Validation of the Scale of Emotional States in the Physical Education Context
}

\author{
Rubén Trigueros $^{1, *}$, José M. Aguilar-Parra ${ }^{1, *}$, Adolfo J. Cangas ${ }^{2} \mathbb{D}$ and Joaquín F. Álvarez ${ }^{1}$ \\ 1 Department of Psychology, Hum-878 Research Team, Health Research Centre, University of Almería, \\ Ctra. Sacramento s/n, 04120 Almería, Spain; jalvarez@ual.es \\ 2 Department of Psychology, Hum-760 Research Team, Health Research Centre, University of Almería, \\ Ctra. Sacramento s/n, 04120 Almería, Spain; ajcangas@ual.es \\ * Correspondence: rtr088@ual.es (R.T.); jmaguilar@ual.es (J.M.A.-P.); Tel.: +34-95-001-5376 (R.T. \& J.M.A.-P.)
}

Received: 14 August 2019; Accepted: 11 September 2019; Published: 12 September 2019

\begin{abstract}
The purpose of the present study was to validate an instrument of student emotional experiences in the Spanish Physical Education context. The sample of participants consisted of 864 secondary education students from various educational institutions of Spain who ranged in age from 13 to 19 years. To assess the psychometric properties of the Scale of Emotions in Physical Education (SEPE), various types of analyses were conducted. The factor structure of the SEPE was examined through confirmatory factorial analysis in relation to two models. In the first model, it was proposed that the eight first order factors, which represented the eight emotional states, would be correlated amongst each other. In the second model, an eight-factor model with two higher order factors was proposed, with these higher order factors representing distinct sets of positive and negative emotions. The results provide support the presence of an eight-factor second order model which consisted of sets of four positive emotions and four negative emotions. These results provide evidence for the reliability and validity of the SEPE within the Spanish Physical Education context.
\end{abstract}

Keywords: emotions; psychometric properties; physical education; cognitive processes

\section{Background}

Considerable advances have been made in recent years in the understanding of psychological and motivational characteristics of students in the Physical Education (PE) context. In this regard, Schutz and Pekrun [1] commented that there has been notable interest displayed by researchers in understanding emotional and affective processes in students. Nonetheless, research to date in this area has been relatively fragmented as there have been theories and corresponding research focused on specific emotions, such as anxiety [2], and studies on the specific effects of certain emotions [3].

Damasio [4] characterized emotion in terms of the collection of psychological and physical responses that have the purpose of reestablishing a state of mental and physical equilibrium in the face of external circumstances or in response to challenging social circumstances. These responses take place spontaneously and automatically and are usually reflected in a series of affective, cognitive, expressive, and motivational components $[5,6]$. Taking anxiety as an example, the affective component refers to the sense of uneasiness and nervous feelings, whereas the cognitive component refers to worry. In turn, the motivational component involves an evasive tendency, or the lack of desire to confront the circumstances that need to be faced. Finally, the expressive component refers to anxious facial expressions or other somatic responses that reflect an underlying state of unease.

The Individual Zones of Optimal Functioning (IZOF) model developed by Hanin [7] argues that emotion is a component of the psycho-biosocial state conceptualized as a situational, multimodal, and dynamic manifestation of human functioning. This model presents five basic dimensions (form, 
content, intensity, time, and context) in order to describe the optimal and dysfunctional structure of the individual, as well as the dynamics of emotional experiences that are related to performance. The model provides the functional explanation of the dynamics of the relationships between emotions and performance based on a detailed description of people's subjective experiences. This in the educational context is especially important because teachers who assist their students in the self-regulation of emotions generally face three problems: (a) the identification of emotional states related to individual performance success versus poor performance; (b) the understanding of the relationships between emotions and performance; and (c) the selection of emotional self-regulation techniques [8].

In general, emotions activate or inhibit certain types of behavior given that people tend to experience common sensations across similar contexts that are associated with positive or negative affect, which can lead to maintenance or dropout from sport [9]. As such, it becomes extremely important to recognize and understand the emotional processes that take place given the evident influence upon academic outcomes. In the Physical Education context, for example, anxiety and boredom have been found to have an inverse relationship with involvement in PE classes [10], and conversely, enjoyment is found to positively correlate with level of involvement in PE [11].

It is essential to have the capacity to effectively measure emotional states given their known influence on the social, emotional, and personal development of individuals in addition to their behavioral implications in various contexts. Pekrun, Goetz, Titz, and Perry [12] developed the Achievement Emotions Questionnaire (AEQ) which assesses emotional valence, activation, and focus at the moment in which the experience takes place. This instrument was designed with reference to three subscales that reflect emotional characteristics in classes, in learning, and in test-taking and consists of a total of 231 items. A direct adaptation of this questionnaire would be problematic given the number of items that it contains. Furthermore, the AEQ was created for the context of the ordinary classroom (e.g., mathematics, literature, science) which differs in its dynamics from Physical Education classes [13]. As such, it is necessary to develop an instrument that is more specific to Physical Education classes.

On the other hand, a shorter instrument to assess emotions in the context of Physical Education is the PANASN (Positive and Negative Affect Schedule; [14]), used in numerous investigations [15,16]. This questionnaire is composed of 20 items distributed in proportion between two factors: positive affection and negative affection. Each of these items refers to a unique emotion; therefore, there is no multidimensional value to value the different emotions expressed by students during EF classes. In addition, the questionnaire confuses emotion with moods [17] and was not designed for application in the field of EF [7].

Various studies have revealed that positive emotional experiences can be accompanied by affective and social benefits and can stimulate personal growth. The authors of the present study reviewed theory and research and sought to identify those emotions that were most likely to be experienced by Physical Education students. The emotions selected included anxiety, which is defined by Eysenck and Fajkowska [18] as a negative emotional state and which is related to worry and nervousness. Based on the State and Trait Anxiety Inventory (STAI), a distinction is made between trait and anxiety state [19]. The trait anxiety is a relatively permanent characteristic of personality, which is reflected in latency to react with the state of anxiety-ness; the state of anxiety is a situational and transitory reaction, characterized specifically by a cognitive state of recurrent worry by the possible failure or bad performance in the task, and by the aversive consequences that it can have on the decrease of one's self-esteem and own social undervaluation. Generally, this reaction leads to feelings of nervousness, tension, and physiological activation [20]. Previous research indicates that anxiety can result from social and familial influences and negative personal experiences among other factors that can increase the likelihood of the appearance of anxiety and extend to affect the level of student involvement in classes of Physical Education [21,22]. By contrast, calmness is an emotional state in which worry is not present during any given moment in time [23]. To date, however, studies of this emotion have yet to be conducted in the Physical Education environment [24,25]. Some research indicates that physical activity contributes to a state of calmness or tranquility either during or following the activity. 
Boredom is also one of the emotions that were included on the instrument. From the psychological paradigm, boredom is often defined as a state of reduced excitement that occurs in a situation of understimulation [26]. More concretely, from an educational constructivist perspective, boredom is defined as a negative emotion that impedes a student's learning experiences [27]. Thus, the perception of boredom is likely to result in less control of attention, slow processing of information, and consequently, in students' resistance to assimilation of content, ability, and school [28]. This emotion has been studied extensively in classes of Physical Education $[29,30]$ and is characterized by a lack of interest or enjoyment and limited motivation to do the activity due to students' perceptions that the level of challenge is low in relation to their ability. A contrasting emotional state is enjoyment, which is reflected in the experience of happiness and enthusiasm. This emotion has been included in various studies [31,32] which generally reveal that when students feel personal control and intrinsic motivation, they are more likely to experience enjoyment in PE classes.

According to the embarrassment theory of Modigliani [33], embarrassment is like a sentiment of fragility because of the belief that one's own self believes they are less competent than others. This emotion is experienced with some assiduity during PE classes, since failure or comparison with others is usually a trigger for that emotion, although it can be attenuated when one's behavior is not as deficient as it seems or there is no eye contact. In this sense, a study by Trigueros et al. [34] shows that students who experience embarrassment during EF classes will feel more inhibited in class, negatively affecting their motivation and reducing their participation in class. A contrasting effect is experienced under circumstances in which students feel confidence. The two main conceptual approaches to the study of confidence are the theory of self-efficacy [35] and the confidence model [36]. Self-efficacy is defined as "the belief in one's own capacities to organize and execute the courses of action required to produce certain achievements" [35]. By extension, confidence is defined as belief in the individual's ability to succeed [36]. Both theories indicate that information that students use to judge their abilities is a critical factor in developing and maintaining a stable level of confidence [35,37]. Various studies $[38,39]$ have demonstrated that this emotion can have an important role in contributing to class involvement during PE classes and subsequent physical activity involvement beyond the school day.

The emotional states of hopelessness and pride are also included in the questionnaire. These emotions refer to the state of mood and illusion in what is being done. According to the theory of hopelessness [40], this emotion is manifested by the presence of negative expectations before a highly valued exit or by feelings of impotence before the improbability of modifying the reached results, being able to manifest this emotion immediately before or after the event. On the other hand, pride refers to positive expectations of oneself or to self-esteem. However, the few studies in the area of Physical Education that have analyzed these emotions [41,42] suggest that hopelessness is negatively related to motivation and vice versa because it is linked to unfavorable perceptions of competence and autonomy in classes. As such, students experiencing hopelessness feel that they will not be able to meet the challenges that are present.

In accordance with these considerations, the present investigation was intended to assess the psychometric properties of an unpublished instrument called the Scale of Emotional States in Physical Education questionnaire (SEPE) (see Appendix A) to determine whether positive and negative emotional states actually represent two distinct categories of emotion during PE classes. The factor structure of the SEPE was examined through confirmatory factory analysis in relation to two models. In the first model, it was proposed that the eight first order factors, which represented the eight emotional states included in the survey, would be correlated amongst each other. In the second model, an eight-factor model with two higher order factors was proposed, with these higher order factors representing distinct sets of positive and negative emotions. In addition, tests of factorial invariance were conducted in relation to gender and the internal consistency of the individual subscales was examined. 


\section{Methods}

\subsection{Participants}

The participants in this study were 864 secondary education students (438 males and 436 females) who ranged in age from 13 to 19 years $(M=15.34 \mathrm{y}, S D=1.12 \mathrm{y})$ and who were in attendance at various educational institutions (public and private) in the south of the province of Almería. In order to assess the temporal stability of the SEPE, a separate independent sample of 281 secondary education students who ranged in age from 15 to 18 years $(M=16.14 \mathrm{y} ; S D=0.78 \mathrm{y})$ was used. These students completed the instrument on two occasions two weeks apart.

\subsection{Instruments}

The SEPE instrument was examined through confirmatory factor analysis to identify the factor structure of the instrument. The stem for each item on the 40-item questionnaire was: "During PE classes ...", and responses were provided along a 7-point scale that ranged from "1" ("completely disagree") to "7" ("completely agree"). We opted for a Likert scale of 1 to 7 because on a scale of only 5 points, respondents tend to avoid the 2 extreme options, thus obtaining very little variation. In this way, adding more levels results in more diverse ratings [43].

\subsection{Procedure}

This study followed all procedural ethics with regard to the ethical treatment of human participants. Permission was requested and approved by the Bioethics Committee in Human Research of the University of Almeria (Ref: UALBIO 2019/014). Furthermore, we obtained written informed consent from the parents/legal guardians of all participants of the study, because they were underage students. Additionally, the parents/legal guardians were previously informed of the objective and the procedure of this study in writing.

In the present study, we made use of the Delphi method (see [44]), which consists of a technique of obtaining information, based on the consultation of experts in an area, in order to obtain the most reliable consensus opinion of the consulted group. These experts are individually submitted to a series of in-depth questionnaires that are interspersed with feedback from the group. In this way, 56 items were initially developed with the intention of developing and including a range of emotional experiences relevant to the Physical Education context. As a first step, four expert researchers with expertise in the study of emotions in PE area were contacted to solicit their participation. These individuals then contributed to the identification of relevant emotions in Physical Education and completed a review of existing instruments $[18,23,25,31,34]$. Fifty-six relevant questionnaire items were developed from this list, while redundant items were not retained.

To evaluate each of the items from the original pool of items, these four individuals then evaluated each of the items for uniqueness and clarity. Items were eliminated from many of the subscales due to a lack of clarity, redundancy or due to overlap with other items which resulted in a final questionnaire that consisted of 40 items. These 40 items were distributed across eight factors and their corresponding subscales.

\subsection{Data Analysis}

An assessment of the psychometric properties of the SEPE was conducted through various statistical processes. As a first step, a confirmatory factor analysis (CFA) was conducted to test the structure of the model comprising eight emotional dimensions with two higher order factors representing the four positive and four negative emotions. Subsequently, a multigroup analysis was conducted to assess invariance relative to gender. Finally, all descriptive statistics were examined, and the internal consistency of the subscale was assessed through Cronbach's alpha statistic. Temporal stability was assessed through intraclass correlations (ICC). Statistical packages SPSS 24.0 and AMOS 21.0 were used to conduct these analyses. 
Given the high value for the Mardia coefficient (314.63) across the various CFAs, the maximum likelihood estimation method was used along with the bootstrapping procedure. In this case, estimates were not greatly affected by normality issues, which were considered robust [45]. For the purpose of accepting or rejecting the proposed models, a set of model fit indices were employed, including: $\chi 2 / d f$, Comparative Fit Index (CFI), Tucker Lewis Index (TLI), Incremental Fit Index (IFI), Root Mean Square Error of Approximation (RMSEA), as well as 90\% confidence intervals (IC) and Standardized Root Mean Square Residual (SRMR).

Given that $\chi 2$ is very sensitive to sample size [46], the value of $\chi 2 / d f$ was also considered with values less than 5.0 considered to be acceptable [47]. The incremental fit indices (CFI, TLI, and IFI) revealed a good fit with values equal to or exceeding 0.90 [48], while the RMSEA and SRMR error indices are considered acceptable if their values are less than $0.08[49,50]$.

\section{Results}

\subsection{Confirmatory Factor Analysis}

The eight-factor structure of the model was examined in relation to the various fit indices and yielded corresponding values of: $\chi 2(712, \mathrm{~N}=864)=2446.07, p=0.001 ; \chi 2 / d f=3.43 ; \mathrm{CFI}=0.85$; $\mathrm{TLI}=0.83 ; \mathrm{IFI}=0.85$; and RMSEA $=0.074(\mathrm{IC} 90 \%=0.071-0.077) ; \mathrm{SRMR}=0.086$. An examination of these fit indices and the residual standardized covariances indicated the possibility of areas for improvement given that residual values of some items correlated with residual values of other items with standardized residual values exceeding 2.00 [46]. Four items were subsequently eliminated from each of the factors of boredom, hopelessness, calmness, and anxiety. Following the elimination of these four items, there was an improvement to the indices of fit: $\chi 2(566, \mathrm{~N}=864)=1352.35, p=0.001$; $\chi 2 / d f=2.39 ; \mathrm{CFI}=0.92 ; \mathrm{TLI}=0.91 ; \mathrm{IFI}=0.92 ; \mathrm{RMSEA}=0.056(\mathrm{IC} 90 \%=0.052-0.060) ;$ and SRMR $=0.067$. In the revised model, the standardized residual values of each of the items were below 2.0, and the standardized factor loadings were statistically significant $(p<0.001)$ and ranged from 0.33 to 0.90 . Subsequently, individual items with loadings below 0.50 were eliminated from two factors (Pride and Enjoyment). Excluding these two items resulted in an improvement to the fit indices in the model: $\chi 2(499, \mathrm{~N}=864)=1018.30, p=0.001 ; \chi 2 / d f=2.04 ; \mathrm{CFI}=0.94 ; \mathrm{IFI}=0.94 ; \mathrm{TLI}=0.94 ; \mathrm{RMSEA}=0.048$ (IC 90\% $=0.044-0.053$ ); and SRMR $=0.048$. This model was finalized as such (Figure 1 ) as each of the standardized residual values were consequently below 2.0, and standardized factor loadings were statistically significant $(p<0.001)$ and ranged between 0.57 and 0.90 .

Following the revision of the model, a higher-order model was examined in which the four positive emotions and the four negative emotions constituted distinct first-order factors. Fit indices for this model were similar to the previously tested model and acceptable: $\chi 2(523, \mathrm{~N}=864)=1013.55$, $p=0.001, \chi 2 / d f=2.11 ; \mathrm{CFI}=0.94 ; \mathrm{TLI}=0.94 ; \mathrm{IFI}=0.94 ; \mathrm{RMSEA}=0.050(\mathrm{IC} 90 \%=0.046-0.054) ;$ and SRMR $=0.065$. Each of the standardized factor loadings was significant $(p<0.001)$, including 0.86 for Shame; 0.87 for Boredom; 0.93 for Hopelessness; and 0.63 for Anxiety for the Negative Emotion constructs. For the Positive Emotion constructs, these weights were 0.69 for Confidence; 0.54 for Calmness; 0.85 for Enjoyment; and 0.67 for Pride. The correlation between the two higher order factors was $r=-0.34$. 


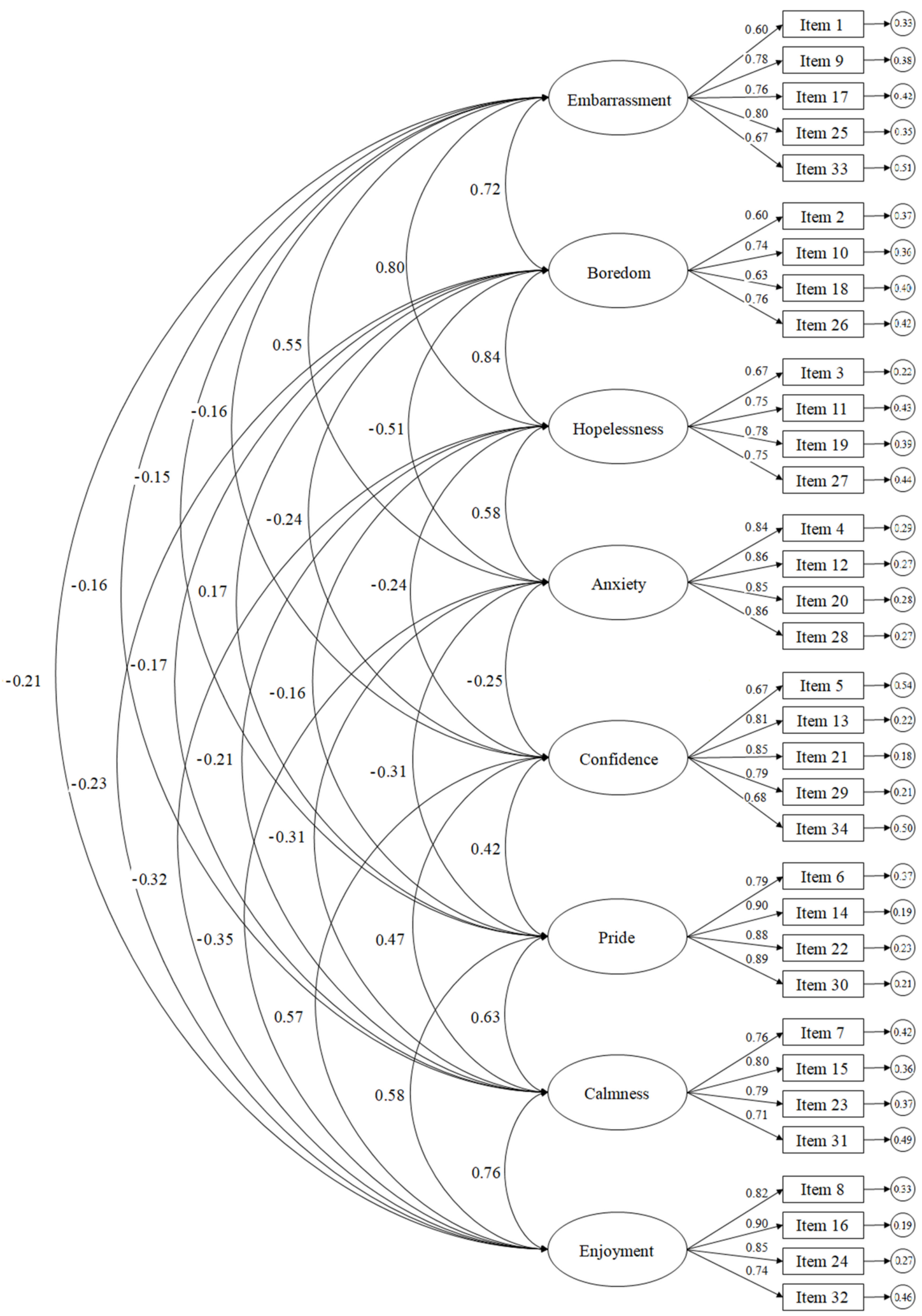

Figure 1. Confirmatory factor analysis of the Scale of Emotions in Physical Education (SEPE). The ellipses represent the factors and the rectangles represent the specific items. Residual variances are presented in the small circles. 


\subsection{Analysis of Gender Invariance}

A multigroup analysis was conducted to compare the factor structures of the eight-factor model with the two-factor, higher-order model. Table 1 displays the various fit indices for each of the models. There were no significant differences between the unrestricted model (Model 1) and the mean weighted invariance model (Model 2). In turn, differences were found between Model 1 (unrestricted model) and Model 3 (structurally invariant covariance model) and between Model 1 and Model 4 (invariant model of mean residuals). The lack of significant differences between Model 1 and Model 2 attained the minimum criteria for acceptance of invariance relative to gender [51].

For the purpose of examining the factor structure of the eight-factor model, as well as the two-factor higher order model, a multigroup analysis of invariance was conducted across gender. Table 1 provides the various fit indices for the various models. For the eight-factor model, significant differences were not found between the unrestricted model (Model 1) and the weighted mean invariance model (Model 2). Differences were encountered between Models 1 and 3 (invariant structural covariance model) and Model 4 (mean residual invariant model). The lack of significant differences between Models 1 and 2 was sufficient to consider the proposed model to be invariant with respect to gender [51].

With respect to the higher-order model, significant differences were not found between the unrestricted model (Model 1), the weighted mean invariance model (Model 2), and the invariant structural covariance model (Model 3). The results indicated significant differences among Models 1 and 4 (mean residual invariant model) as well as with Model 5. These results provide support as well for invariance across gender for the higher-order model.

Table 1. Multigroup invariance model across gender.

\begin{tabular}{|c|c|c|c|c|c|c|c|c|c|c|}
\hline \multicolumn{11}{|c|}{ Eight-factor first order model } \\
\hline Models & $\chi^{2}$ & $d f$ & $\chi 2 / d f$ & $\Delta \times 2$ & $\Delta d f$ & CFI & TLI & IFI & $\begin{array}{l}\text { RMSEA } \\
\text { (IC 90\%) }\end{array}$ & SRMR \\
\hline Model 1 & 1653.95 & 998 & 1.66 & & & 0.94 & 0.94 & 0.94 & 0.039 & 0.042 \\
\hline Model 2 & 1684.27 & 1024 & 1.65 & 30.32 & 26 & 0.93 & 0.93 & 0.93 & 0.038 & 0.041 \\
\hline Model 3 & 1760.28 & 1060 & 1.66 & 106.33 & $62 * *$ & 0.93 & 0.92 & 0.93 & 0.039 & 0.042 \\
\hline Model 4 & 1889.14 & 1094 & 1.72 & 235.19 & $96^{* *}$ & 0.91 & 0.92 & 0.91 & 0.041 & 0.045 \\
\hline \multicolumn{11}{|c|}{ Two-factor higher order model } \\
\hline Models & $x^{2}$ & $d f$ & $\chi 2 / d f$ & $\Delta \chi^{2}$ & $\Delta \mathrm{df}$ & CFI & TLI & IFI & $\begin{array}{l}\text { RMSEA } \\
(\text { IC 90\%) }\end{array}$ & SRMR \\
\hline Model 1 & 1759.59 & 1046 & 1.68 & & & 0.92 & 0.92 & 0.92 & 0.039 & 0.079 \\
\hline Model 2 & 1795.06 & 1072 & 1.68 & 35.48 & 26 & 0.92 & 0.92 & 0.92 & 0.039 & 0.079 \\
\hline Model 3 & 1797.79 & 1073 & 1.68 & 38.20 & 27 & 0.92 & 0.92 & 0.92 & 0.039 & 0.079 \\
\hline Model 4 & 1807.69 & 1076 & 1.68 & 48.10 & $30 *$ & 0.92 & 0.92 & 0.92 & 0.039 & 0.081 \\
\hline Model 5 & 1835.34 & 1084 & 1.69 & 75.75 & $38 * *$ & 0.92 & 0.92 & 0.92 & 0.040 & 0.081 \\
\hline Model 6 & 1965.44 & 1118 & 1.76 & 205.85 & $72 * *$ & 0.91 & 0.91 & 0.91 & 0.041 & 0.082 \\
\hline
\end{tabular}

\subsection{Descriptive Statistics}

As can be observed in Table 2, the mean values overall for the positive emotions were higher than the mean values for negative emotions, with the Confidence subscale demonstrating the highest individual subscale mean value $(M=4.94)$. Negative emotion subscales demonstrated lower overall means, most notably on the Hopelessness subscale $(M=1.97)$. 
Table 2. Descriptive statistics and bivariate correlations.

\begin{tabular}{|c|c|c|c|c|c|c|c|c|c|c|}
\hline Factor & $\mathbf{M}$ & SD & 1 & 2 & 3 & 4 & 5 & 6 & 7 & 8 \\
\hline 1. Embarrassment & 2.35 & 0.96 & & $0.56^{* *}$ & $0.67^{* *}$ & $0.50^{* *}$ & $-0.12 *$ & $-0.13^{* *}$ & $-0.14^{* *}$ & $-0.18^{* *}$ \\
\hline 2. Boredom & 2.44 & 1.05 & & & $0.66^{* *}$ & $0.41^{* *}$ & $-0.15^{* *}$ & $-0.18^{* *}$ & $-0.16^{* *}$ & $-0.23^{* *}$ \\
\hline 3. Hopelessness & 1.97 & 1.05 & & & & $0.51^{* *}$ & $-0.14^{* *}$ & $-0.21^{* *}$ & $-0.19^{* *}$ & -0.27 ** \\
\hline 4. Anxiety & 2.11 & 1.23 & & & & & $-0.22 * *$ & $-0.22 * *$ & $-0.29 * *$ & $-0.31^{* *}$ \\
\hline 5. Pride & 4.82 & 1.55 & & & & & & $0.38^{* *}$ & $0.59 * *$ & $0.51^{* *}$ \\
\hline 6. Confidence & 4.94 & 1.27 & & & & & & & $0.42^{* *}$ & $0.50^{* *}$ \\
\hline 7. Calmness & 4.61 & 1.44 & & & & & & & & $0.68^{* *}$ \\
\hline 8. Enjoyment & 4.60 & 1.26 & & & & & & & & \\
\hline
\end{tabular}

\subsection{Assessment of Internal Consistency and Temporal Stability}

An assessment of the internal consistency of the scale was subsequently conducted, as well as an assessment of the scale's stability over time. Cronbach's alpha statistic was used to assess internal consistency and the associated alpha values for the subscales that were: 0.76 for Boredom, 0.82 for Hopelessness, 0.84 for Embarrassment, 0.85 for Enjoyment, 0.86 for Pride, 0.90 for Confidence, 0.91 for Anxiety, and 0.92 for Calmness. For the entire positive and negative emotions subscales, the associated Cronbach alpha values were 0.80 for the positive emotions scale and 0.82 for the negative emotions scale.

With regard to the analysis of temporal stability, an independent sample was used in which intraclass correlation coefficients (ICC) and confidence intervals (CI) were examined. For the analysis of temporal stability, data from an independent sample were obtained on two separate occasions, and the findings were assessed with regard to intraclass correlation coefficients (ICC) and confidence intervals (CI). Temporal stability was supported for each of the SEPE subscales, including Embarrassment $=0.85$ $(\mathrm{CI}=0.81-0.90) ;$ Pride $=0.85(\mathrm{CI}=0.82-0.89) ;$ Boredom $=0.88(\mathrm{CI}=0.87-0.93) ;$ Hopelessness $=0.86$ $(\mathrm{CI}=0.80-0.94) ;$ Anxiety $=0.86(\mathrm{CI}=0.82-0.91) ;$ Confidence $=0.82(\mathrm{CI}=0.77-0.88) ;$ Calmness $=0.87$ $(\mathrm{CI}=0.86-0.91) ;$ and Enjoyment $=0.78(\mathrm{CI}=0.75-0.81)$.

\section{Discussion}

The purpose of the present study was to develop an appropriate instrument for the measurement of those emotional states that are most commonly experienced in the Physical Education environment. Eight different emotional states were included: embarrassment, anxiety, boredom, hopelessness, hope, enjoyment, confidence, and calmness.

To conduct the analyses, it was necessary to examine various psychometric indices including factor validity, internal consistency, and temporal stability of the SEPE instrument. The goal was to create a practical and brief questionnaire which appropriately represented the positive and negative types of emotions that students most commonly experience in classes of Physical Education. This process led to the generation of a valid and reliable instrument that is multidimensional and which was invariant for males and females.

The confirmatory factor analysis provided support for a 34-item eight factor model for the SEPE. Fit indices were acceptable, and temporal stability was also in evidence. The subscales attained adequate internal consistency, with Cronbach alpha values exceeding 0.70 , which is commonly accepted as reflective of internal consistency [52]. The confirmatory factor analysis revealed that the set of negative emotions were correlated positively amongst each other, as was the set of positive emotions. The positive and negative emotions were inversely correlated with each other, as anticipated.

In accordance with these findings, it seems probable that the Physical Education context evokes various emotional responses among students as an outgrowth of their own personal experiences in this context and in relation to the favorability of their interactions with teachers and peers, among other factors. In turn, students' psychological well-being is likely to be influenced by the nature of these 
experiences [10,53]. It is also likely that the satisfaction of psychological needs in Physical Education would contribute to the development of emotional growth and a resulting improvement in student perceptions of Physical Education classes. Logically, more favorable emotional experiences should extend to other additional educational settings beyond a given Physical Education classroom [54]. In addition, greater involvement in regular physical activity outside of the classroom might also result from a more favorable perception of their experiences in Physical Education.

An additional important finding from the present investigation was that the CFA results supported the existence of a two factor higher-order model in which positive emotions and negative emotions loaded on different factors. From a methodological point of view, this knowledge could result in the use of emotional assessment specific to either positive or negative emotions, if needed. In this sense, this result is shown according to the IZOF model [7], where it is stated that emotions possess a high degree of interindividual variability in the intensity and content that accompany successful and deficient individual performances. In this way, and according to the model, students can present positive and negative emotions depending on the individual differences in the level of available resources, the capacity of the students to efficiently achieve and use their motor skills, and the individual capacity of the students to compensate for the lack or insufficiency of knowledge and motor skills (little preparation for an exam or activity). The use of the global measure could prove worthwhile where emotional characteristics in PE are examined in relation to other variables. It should also be noted that the two-factor higher order model, as well as the eight-factor model, demonstrated invariance across gender and acceptable internal consistency of each subscale.

\section{Limitations}

Although the results of the present student provided psychometric support for the SEPE, there are also a few limitations that should be noted. First, the present sample was one of convenience, and thus, this pattern of findings should be examined with other groups of students who may vary by age, grade, and other variables given that instrument validation is a continuous process. Second, future research could attempt to determine the predictive validity of the instrument through comparison with studies using similar scales (e.g., AEQ), as well as to attempt to identify and determine psychological and behavioral predictors towards commitment to PE classes, adherence to physical activity practice, adoption of a healthy lifestyle, prosocial skills, etc.

\section{Conclusions}

In closing, the findings from the present study provided support for the validity and reliability of the SEPE instrument as a multidimensional measure of emotion in Physical Education classes. It is essential that we recognize the importance of assessing emotional states in our students in these classes so that we can better understand how to increase the likelihood of favorable and reduce the likelihood of unfavorable emotional experiences in this context. By doing so, we can increase the likelihood that these individuals will engage in physical activity outside of the school context and improve their quality of life.

Author Contributions: Conceptualization, J.F.Á.; Methodology, R.T. and J.M.A.-P.; Project administration, A.J.C.; Resources, J.F.Á.; Visualization, A.J.C.; Writing—original draft, R.T.; Writing—review and editing, J.M.A.-P., and R.T.

Funding: This research received no external funding.

Conflicts of Interest: The authors declare no conflict of interest. 


\section{Appendix A}

Scale of Emotions in Physical Education (SEPE)

Embarrassment
1. I feel like a fool
9. My companions make me feel embarrassed
17. I feel embarrassed because I don't know if I am capable of performing the exercises
25. I feel like a fool because my colleagues can do it and I can't
33. I feel embarrassed when I participate

\section{Boredom}

2. I am usually bored

10. The exercises seem quite repetitive

18. Time slows down

26. My mind wanders due to boredom

\begin{tabular}{l} 
Hopelessness \\
\hline 3. I feel that I am going to fail \\
11. I feel useless \\
19. I feel frustrated and useless \\
27. I feel beaten down
\end{tabular}

\section{Anxiety}

4. I feel very anxious

12. I feel very nervous

20. I feel uncomfortable when I think I am being evaluation

28. I feel pressure in my chest when it is my turn to do the exercises

\section{Confidence}

5. I know that I am capable of doing the exercises

13. I feel prepared to accomplish the exercises

21. I am confident in my capacity and ability

29. I love new challenges because I know that I can accomplish them porque

34. I am confident that I will be successful

\section{Pride}

6. I feel proud when the others demonstrate that they value me

14. I feel proud when I do well in class

22. I feel proud when I able able to meet challenges

30. I feel proud when I am able to complete exercise in class better than the others

\section{Calmness}

7. I feel relaxed before participating

15. I feel a sense of calmness while doing the exercises

23. I get rid of the tension that I was feeling

31. Little by little, I feel that I am relaxing

\section{Enjoyment}

8. I usually enjoy the exercises

16. I feel that class time passes by very quickly

24. I really enjoy the exercises

32. I usually find the exercises to be interesting 


\section{References}

1. Schutz, P.A.; Pekrun, R. Emotion in Education; Elsevier Academic Press: Boston, MA, USA, 2007.

2. Russell, G.; Topham, P. The impact of social anxiety on student learning and well-being in higher education. J. Ment. Health 2012, 21, 375-385. [CrossRef] [PubMed]

3. Lagardera, F.; Lavega, P. Educación Física, conductas motrices y emociones. Ethol. Praxéol. 2013, 16, $23-43$.

4. Damasio, A. En busca de Spinoza: Neurobiología de la emoción y los sentimientos. In Search of Spinoza: Neuobiology of Emotion and Feelings; Crítica: Barcelona, Spain, 2005.

5. Denham, S.A.; Bassett, H.H.; Zinsser, K. Early Childhood Teachers as Socializers of Young Children's Emotional Competence. Early Child. Educ. J. 2012, 40, 137-143. [CrossRef]

6. Meyer, D.K.; Turner, J.C. Scaffolding emotions in classrooms. In Emotion in Education; Elsevier Inc.: Amsterdam, The Netherlands, 2007; pp. 243-258.

7. Hanin, Y.L. Emotions in Sport; Human Kinetics: Champaign, IL, USA, 2000.

8. Robazza, C.; Melinda, P.; Hanin, Y. Emotion self-regulation and athletic performance: An application of the IZOF model. Psychol. Sport Exerc. 2004, 5, 379-404. [CrossRef]

9. Deci, E.L.; Ryan, R.M. Self-determination theory. In Handbook of Theories of Social Psychology; Oxford University Press: Oxford, UK, 2012; pp. 416-437.

10. Yli-Piipari, S.; Watt, A.; Jaakkola, T.; Liukkonen, J.; Nurmi, J. Relationships between physical education students' motivational profiles, enjoyment, state anxiety, and self-reported physical activity. J. Sports Sci. Med. 2009, 8, 327-336. [PubMed]

11. Braithwaite, R.; Spray, C.M.; Warburton, V.E. Motivational climate interventions in physical education: A meta-analysis. Psychol. Sport Exerc. 2011, 12, 628-638. [CrossRef]

12. Pekrun, R.; Goetz, T.; Titz, W.; Perry, R.P. Academic Emotions in Students' Self-Regulated Learning and Achievement: A Program of Qualitative and Quantitative Research. Educ. Psychol. 2002, 37, 91-105. [CrossRef]

13. Meltzer, M.W. Instructional Models in Physical Education, 3rd ed.; Routledge Ltd.: London, UK, 2017.

14. Sandín, B. PANAS scales of positive and negative affection for children and adolescents (PANASN). J. Psychop. Clin. Psychol. 2003, 8, 173-182.

15. Martin, J.J.; Kulinna, P.H. A social cognitive perspective of physical activity related behavior in physical education. J. Teach. Phys. Educ. 2005, 24, 265-281. [CrossRef]

16. Méndez-Giménez, A.; Cecchini-Estrada, J.A.; Fernández-Río, J. Perfectionism, affectivity and life satisfaction in physical education. RICYDE. Int. J. Sport Sci. 2015, 11, 297-304.

17. Ekman, P.; Davidson, R.J. The Nature of Emotion; Oxford University Press: Oxford, UK, 1994.

18. Eysenck, M.W.; Fajkowska, M. Anxiety and depression: Toward overlapping and distinctive features. Cogn. Emot. 2017, 32, 1391-1400. [CrossRef] [PubMed]

19. Spielberger, C.; Gorsuch, R.; Lushene, R. STAI, Manual for the State-Trait Anxiety Inventory (Self Evaluation Questionnaire); Adaptacion española. Madrid: Seccion de Estudio de Tests. TEA Ediciones S.A.; Consulting Psychologists Press: Palo Alto, CA, USA, 1982.

20. Gutiérrez, M. Ansiedad y deterioro cognitivo: Incidencia en el rendimiento académico. Ansiedad Estrés 1996, 2, 173-194.

21. Coterón, J.; Franco, E.; Pérez, J.; Sampedro, J. Clima motivacional, competencia percibida, compromiso y ansiedad en Educación Física. Diferencias en función de la obligatoriedad de la enseñanza. Rev. Psicol. Deporte 2013, 22, 151-157.

22. Han, D.H.; Kim, S.M.; Zaichkowsky, L. Insecure attachment and anxiety in student athletes. J. Sports Med. Phys. Fit. 2013, 53, 274-282.

23. Williams, D.M.; Dunsiger, S.; Ciccolo, J.T.; Lewis, B.A.; Albrecht, A.E.; Marcus, B.H. Acute affective response to a moderate-intensity exercise stimulus predicts physical activity participation 6 and 12 months later. Psychol. Sport Exerc. 2008, 9, 231-245. [CrossRef] [PubMed]

24. Jiménez-Oviedo, Y.; Núñez, M.; Coto-Vega, E. La actividad física para el adulto mayor en el medio natural. Inter Sedes Rev. Sedes Reg. 2013, 14, 168-181.

25. Granero-Gallegos, A.; Extremera, A.B.; de Deus Inácio, H.L.; Bracho-Amador, C.; Pérez-Quero, F.J. Analysis of the Spanish version of the Sport Satisfaction Instrument (SSI) adapted to Physical Education. Mot. Rev. Educ. Fis. 2013, 19, 55-61. [CrossRef] 
26. Götz, T.; Hall, N.C. Academic boredom. In International Handbook of Emotions in Education; Routledge: London, UK, 2014; pp. 321-340.

27. Craig, S.; Graesser, A.; Sullins, J.; Gholson, B. Affect and learning: An exploratory look into the role of affect in learning with AutoTutor. J. Educ. Media 2004, 29, 241-250. [CrossRef]

28. Vogel-Walcutt, J.J.; Fiorella, L.; Carper, T.; Schatz, S. The definition, assessment, and mitigation of state boredom within educational settings: A comprehensive review. Educ. Psychol. Rev. 2012, 24, 89-111. [CrossRef]

29. Cecchini-Estrada, J.A.; Fernández-Río, J.; Méndez-Giménez, A.; González-González, C. Autodeterminación y metas sociales: Un modelo estructural para comprender la intención de práctica, el esfuerzo y el aburrimiento en Educación Física. Aula Abierta 2012, 40, 51-62.

30. Garn, A.C.; Cothran, D. The Fun Factor in Physical Education. J. Teach. Phys. Educ. 2006, 25, $281-297$. [CrossRef]

31. Gómez-Mármol, A. Relación entre la autopercepción de la imagen corporal y las clases de Educación Física, según su nivel de intensidad y diversión, en alumnos de educación secundaria. Mot. Rev. Cienc. Act. Fis. Deporte 2013, 31, 99-109.

32. Moreno, J.A.; Hernández, A.; González-Cutre, D. Complementando la teoría de la autodeterminación con las metas sociales: Un estudio sobre la diversión en educación física. Rev. Mex. Psicol. 2009, 26, 213-222.

33. Modigliani, A. Embarrassment, facework, and eye contact: Testing a theory of embarrassment. J. Pers. Soc. Psychol. 1971, 17, 15-24. [CrossRef]

34. Trigueros, R.; Aguilar-Parra, J.M.; Cangas, A.J.; López-Liria, R.; Álvarez, J.F. Influence of Physical Education Teachers on Motivation, Embarrassment and the Intention of Being Physically Active During Adolescence. Int. J. Environ. Res. Public Health 2019, 16, 2295. [CrossRef]

35. Bandura, A. Self-Efficacy: The Exercise of Control; Freeman: New York, NY, USA, 1997.

36. Vealey, R.S.; Chase, M.A. Self-confidence in sport: Conceptual and research Advances. In Advances in Sport Psychology, 3rd ed.; Horn, T.S., Ed.; Human Kinetics: Champaign, IL, USA, 2008; pp. 65-97.

37. Vealey, R.S.; Garner-Holman, M.; Hayashi, S.W.; Giacobbi, P. Sources of sport-confidence: Conceptualization and instrument development. J. Sport Exerc. Psychol. 1998, 20, 54-80. [CrossRef]

38. Bailey, R. Physical Education and Sport in Schools: A Review of Benefits and Outcomes. J. Sch. Health 2006, 76, 397-401. [CrossRef]

39. Standage, M.; Duda, J.L.; Ntoumanis, N. A Model of Contextual Motivation in Physical Education: Using Constructs from Self-Determination and Achievement Goal Theories to Predict Physical Activity Intentions. J. Educ. Psychol. 2003, 95, 97-110. [CrossRef]

40. Nusslock, R.; Shackman, A.J.; Harmon-Jones, E.; Alloy, L.B.; Coan, J.A.; Abramson, L.Y. Cognitive vulnerability and frontal brain asymmetry: Common predictors of first prospective depressive episode. J. Abnorm. Psychol. 2011, 120, 497-503. [CrossRef]

41. Mouratidis, A.; Vansteenkiste, M.; Lens, W.; Auweele, Y.V. Beyond positive and negative affect: Achievement goals and discrete emotions in the elementary physical education classroom. Psychol. Sport Exerc. 2009, 10, 336-343. [CrossRef]

42. Taliaferro, L.A.; Rienzo, B.A.; Pigg, R.M.; Miller, M.D.; Dodd, V.J. Associations Between Physical Activity and Reduced Rates of Hopelessness, Depression, and Suicidal Behavior Among College Students. J. Am. Coll. Health 2009, 57, 427-436. [CrossRef]

43. Boari, G.; Nai-Ruscone, M. A procedure simulating Likert scale item responses. Electron. J. Appl. Stat. Anal. 2015, 8, 288-297.

44. Linstone, H.A.; Turoff, M. The Delphi Method; Addison-Wesley Pub.: Boston, MA, USA, 2002.

45. Byrne, B.M. Structural Equation Modeling with AMOS: Basic Concepts, Applications, and Programming; Routledge: London, UK, 2001.

46. Joreskog, K.G.; Sorbom, D. LISREL 8: Structural Equation Modeling with the SIMPLIS Command Language; Lawrence Erlbaum Associates Publishers: Hilldale, NJ, USA, 1993.

47. Bentler, P.M. EQS Structural Equations Program Manual; Multivariate Software: Encino, CA, USA, 1989.

48. Schumacker, R.E.; Lomax, R.G. A Beginner's Guide to Structural Equation Modeling; Routledge: New York, NY, USA, 1996.

49. Browne, M.W.; Cudeck, R. Alternative Ways of Assessing Model Fit. Soc. Methods Res. 1992, 21, $230-258$. [CrossRef] 
50. Hu, L.; Bentler, P.M. Cutoff criteria for fit indexes in covariance structure analysis: Conventional criteria versus new alternatives. Struct. Equ. Model. 1999, 6, 1-55. [CrossRef]

51. Marsh, H.W. The Multidimensional Structure of Academic Self-Concept: Invariance over Gender and Age. Am. J. Educ. Res. 1993, 30, 841-860. [CrossRef]

52. Cicchetti, D.V. Guidelines, Criteria, and Rules of Thumb for Evaluating Normed and Standardized Assessment Instruments in Psychology. Psychol. Assess. 1994, 6, 284-290. [CrossRef]

53. Winefield, H.R.; Gill, T.K.; Taylor, A.W.; Pilkington, R.M. Psychological well-being and psychological distress: Is it necessary to measure both? Psychol. Well Theory Res. Pract. 2012, 2, 3-12. [CrossRef]

54. Keller, M.; Frenzel, A.E.; Goetz, T.; Pekrun, R.; Hensley, L. Exploring teacher emotions. A literatura review and an experience sampling study. In Teacher Motivation. Theory and Practice; Routledge: New York, NY, USA, 2014; pp. 69-82.

(C) 2019 by the authors. Licensee MDPI, Basel, Switzerland. This article is an open access article distributed under the terms and conditions of the Creative Commons Attribution (CC BY) license (http://creativecommons.org/licenses/by/4.0/). 